\title{
VOLTAGE AND FREQUENCY CONTROL FOR HYBRID STAND-ALONE POWER SYSTEMS FOR ISOLATED COMMUNITIES
}

\author{
Adebayo Adeniyi D. ${ }^{1}$ and Christian Adi \\ ${ }^{1}$ Department of Electrical Electronic Engineering, Federal University Otuoke, P.M.B. 126 \\ Yenagoa, Bayelsa State, Nigeria. Email: aadeniyiadebayo@gmail.com \\ ${ }^{2}$ Department of Mechanical Engineering, Federal University Otuoke, P.M.B. 126 Yenagoa, \\ Bayelsa State, Nigeria. Email: manfredrayner456@gmail.com
}

Cite this article:

Adebayo A.D., Christian A. (2021), Voltage and

Frequency Control for Hybrid Stand-Alone Power Systems

For Isolated Communities. Advanced Journal of Science, Technology and Engineering 1(1), 8-28. DOI: 10.52589/AJSTE-

QAXNEWUM.

\section{Manuscript History}

Received: 12 June 2021

Accepted: 9 July 2021

Published: 14 Nov 2021

Copyright $\odot 2020$ The Author(s). This is an Open Access article distributed under the terms of Creative Commons AttributionNonCommercial-NoDerivatives 4.0 International (CC BY-NC-ND 4.0 ), which permits anyone to share, use, reproduce and redistribute in any medium, provided the original author and source are credited.
ABSTRACT: This paper proposes a control and overall coordination of a hybrid stand-alone power system. The system may comprise a wind turbine, fuel cell, electrolyzer, battery storage, diesel generator and a set of loads. The overall control planning of the hybrid system is based on a two-level structure. The top-level is the energy management and power regulation system. Depending on wind and load conditions, this system generates reference dynamic operating points to low-level individual sub-systems. The energy management and power regulation system also controls the load scheduling operation during unfavourable wind conditions with inadequate energy storage in order to avoid a system black-out. Based on the reference dynamic operating points of the individual sub-systems, the local controllers control the wind turbine, fuel cell, electrolyzer and battery storage units. The proposed control system is implemented in MATLAB Simpower software and tested for various wind and load conditions. Results are presented and elucidated.

KEYWORDS: Voltage, Frequency, Voltage and Frequency Control, Hybrid Stand Alone Power System and Isolated Communities. 


\section{INTRODUCTION}

Power utilities in many countries around the world are shifting their attention toward more energy-efficient and renewable electric power sources. Photovoltaic (PV) energy systems are becoming more and more common among all renewable energy sources. Proper control algorithm is required to operate the PV system for residential applications because the nature of solar irradiance and load rapidly changes (Gangnon,2005). Most rural communities and isolated small islands do not benefit from the main grid supply. Presently, energy demand for such locations is mostly supplied through diesel generation systems. However, the operation of such systems has now become a challenge due to the growing environmental concerns and high operating costs. Instead, a hybrid stand-alone power system would be an attractive solution. Such power systems consist of several renewable energy sources such as wind, solar and hydro. Depending on the availability of resources, a suitable combination of renewable energy sources can be utilised to form the hybrid stand-alone power system (Holdsworth,2003). Autonomous wind power systems can be used to meet the increasing electricity demand in remote locations where the wind is freely available. However, there are various challenges associated with designing such power systems. In this regard, voltage and frequency are the most important aspects to be controlled. In addition, power quality issues, coordination among different components and cost-effectiveness are some of the aspects which are still major subjects of interest.

Wind generators require regular maintenance and are susceptible to damage in strong winds. However, PV power fluctuates depending on the weather conditions, season, and geographic location, and may cause problems like voltage fluctuation and large frequency deviation in electric power system operation. It has been demonstrated that hybrid energy systems can significantly reduce the total life cycle cost of stand-alone power supplies in many situations, while at the same time providing a more reliable supply of electricity through the combination of energy sources. Usually, an energy storage system (i.e., battery) is used to smooth the PV output power fluctuations and then the smoothed power is supplied to the utility. This paper concentrates on the control and application of PV-battery hybrid energy systems, which account for the majority of systems installed today. Four different system configurations are widely developed in stand-alone PV power applications: the centralized inverter system, the string inverter system, the multi-string inverter system and the module-integrated inverter system (Senjyu, 2005). Generally, centralized inverter systems can be employed for small-scale distributed generation (DG) systems, such as residential power applications. Residential loads are mostly single-phase loads, moreover, inverter output has harmonics, in order to reduce harmonic content, an LC filter is connected between loads and inverter (Ackermann, 2002). However, all residential loads consume reactive power. Inverter alone cannot provide reactive power required by the load.

\section{Hybrid power systems}

With the increase in power demand and the problem of power generation, distribution, and usages, renewable energy technologies can play an important role in future power supply as a result of increased awareness of environmental pollution (Ozpineci et al,2007). In the case of the power supply systems to remote and isolated communities, renewable energy-based standalone power systems can be a particularly attractive cost-effective solution, as grid extension is often impractical due to economic and technical constraints. Diesel generators are widely used as a stand-alone power supply system application to remote and isolated communities for 
their reliability, cheap installation, ease of starting, compact power density and portability. However, rising fuel prices make them quite expensive to run. Apart from that, they also cause significant environmental pollutions. In most remote and isolated areas, renewable energy sources such as wind and solar are available, which can provide clean cost-effective power (Hussein, 2005).

Structure of Hybrid System: A well-defined framework of a hybrid system is vital, as various energy sources may have different operating characteristics. In an optimal framework, the renewable energy sources, energy storage, and loads are integrated and capable of operating as a unit (Enslin,2001). A robust system should also have a "plug-and-play" capability which renders the system capable of integrating any number of devices without system reconfiguration. There are many ways to integrate different energy sources and storage to form a hybrid power system. Among them, dc-coupled, ac-coupled and hybrid-coupled are the most popular options, which outlined as below:

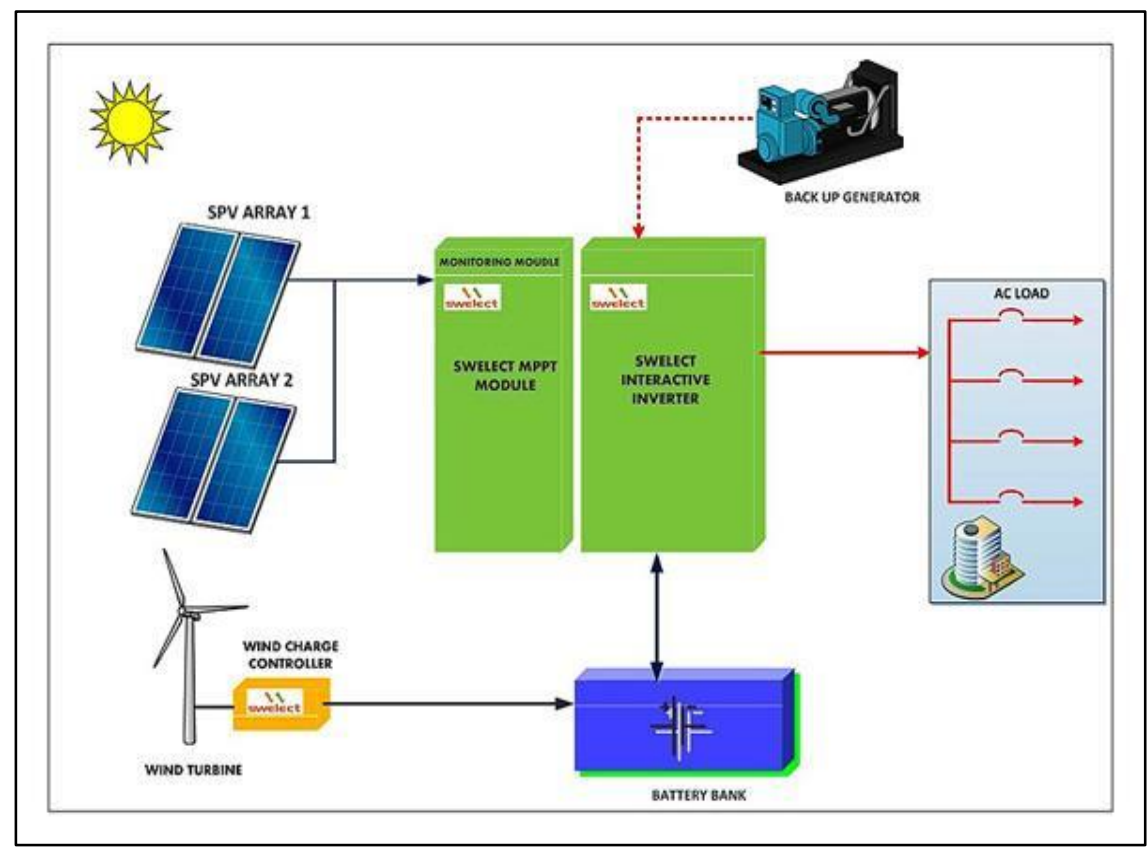

Figure 1: Hybrid power system (Maimone, 2010)

\section{DC-Coupled Systems}

In a dc-coupled system, all renewable energy sources are connected to a dc bus through appropriate power electronic converters (Kiehne,2009). This system can be connected to the dc loads through an appropriate dc-dc converter, ac loads through a dc-ac converter or a utility grid through a bi-directional dc-ac converter. The system is easy and can be connected to an ac load of 50/60 Hz frequency. The dc-coupling scheme is very easy and is not involved to be synchronous with the ac system. However, a dc-coupled system suffers from various weaknesses (Liang,2010). For example, if the system converter connecting the utility grid with the bus is out of service, the whole system will not be able to supply ac power. To rectify this, 
several inverters can be connected in parallel. As such, synchronization of output ac voltage and proper power-sharing are required to achieve the desired load distribution.

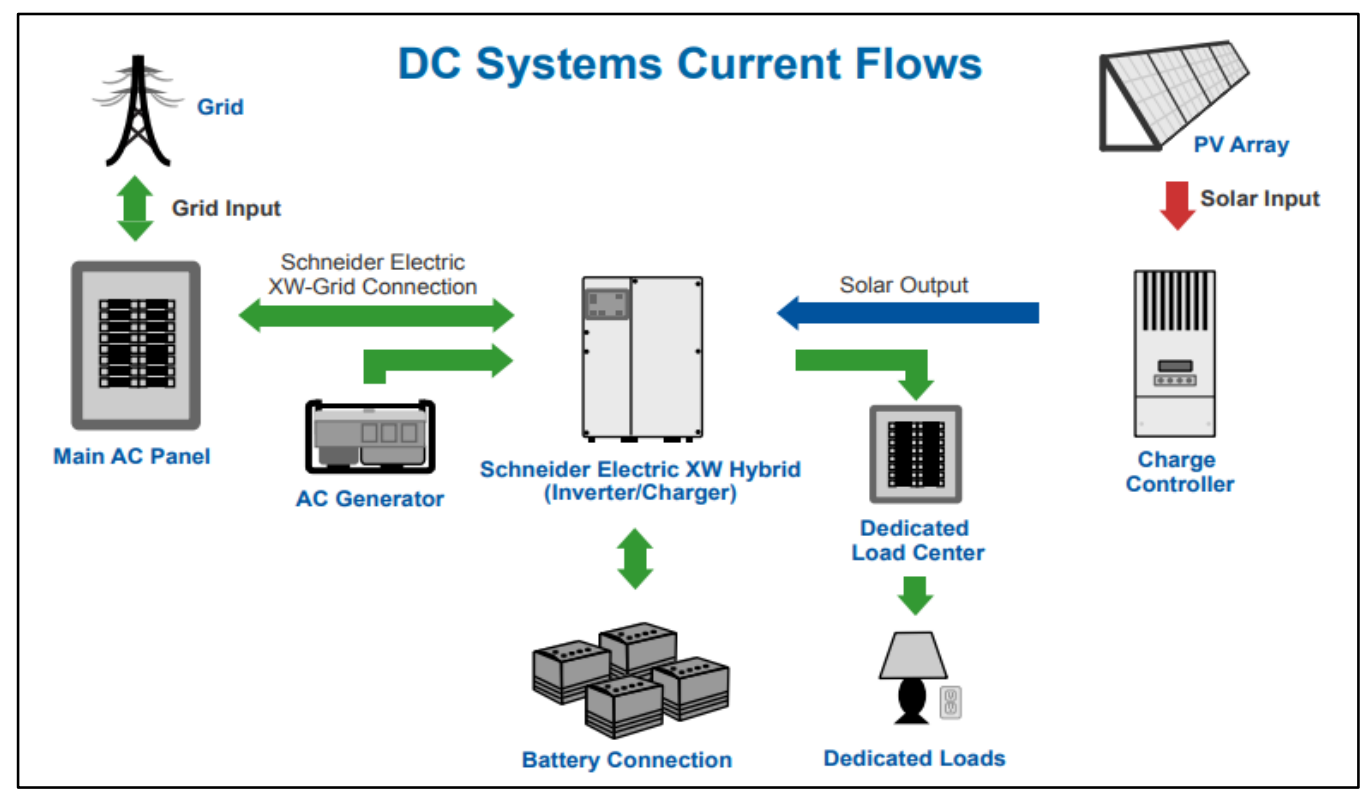

Figure 2: Dc coupled system (Kiehne, 2009)

AC-Coupled Systems: AC-coupled PV systems are gaining wider acceptance and support through several battery-based inverter manufacturers. In AC-coupled systems, the DC power from the array is first converted to AC by a batteryless inverter, to be used by the AC loads through an AC load panel (Markvart,2003).

Hybrid-Coupled Systems: In a hybrid-coupled system, various DG sources are connected to the $\mathrm{dc}$ or ac buses of the hybrid system. In this application, some energy sources can be implemented directly without the use of a power electronic interfacing system.

Stand-alone systems: Stand-alone PV systems or directly coupled PV systems are designed and sized to supply DC and/or AC electrical loads (Esram, 2007). It is called a direct-coupled system because the DC output of a PV module or array is directly connected to a DC load. There is no electrical energy storage (batteries) in direct-coupled systems as because of that, the load only operates during sunlight hours. 


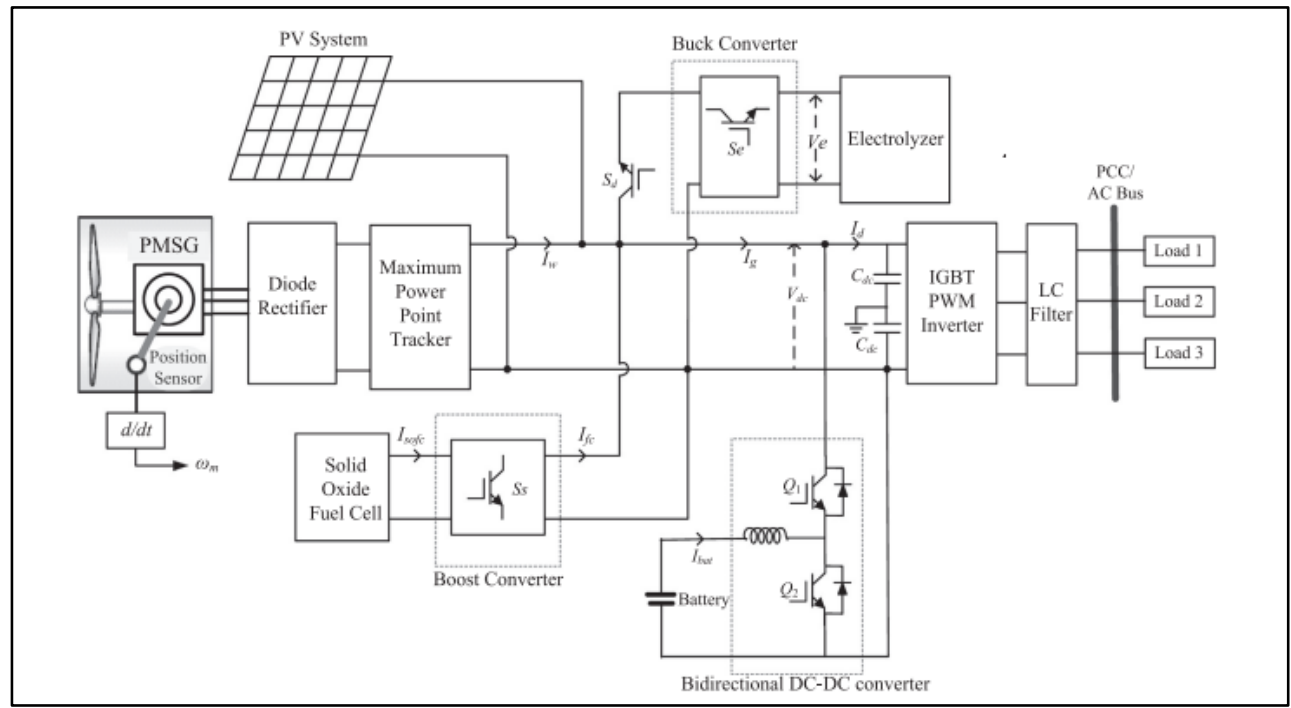

Figure 3: Stand-Alone system

Voltage control and frequency control: The voltage of the generator is proportional to the speed and excitation (flux) of the generator. The speed is constant, the excitation is used to control the voltage (Rashid,2006). Therefore, the voltage control system is also called an excitation control system or automatic voltage regulator (AVR) The control of voltage and reactive power is a major issue in power system operation. This is because of the topological differences between distribution and transmission systems, different strategies have evolved.

Frequency Control: Frequency all over a synchronous power grid is the same in steady-state. Maintaining a near-constant frequency (one may allow the frequency to vary over a very narrow band) is considered an important requirement of power system operation. Frequency in a power system is related to the electrical speed of synchronous generators. The difference between mechanical and electrical torques governs the acceleration of a rotor of a generator.

\section{EMPIRICAL REVIEW}

A similar stand-alone hybrid energy system is presented earlier by few researchers. In Abbey, 2007 authors present the generation of hydrogen using different sources, however, authors did not mention voltage and frequency control of the stand-alone system. In Wasiak, 2008, the author presents an overall power management strategy among different sources and storage units. However, in Singh, 2011, the actual control of the inverter is not available presented. In his work, Kassem, 2008 presents an adaptive control for voltage and frequency regulation of a stand-alone hybrid wind-diesel power system based on constrained linear model predictive control (MPC).

In Gangnon, 2005, the authors proposed an energy management system for a stand-alone power generation system; however, the authors did not consider unbalanced load and power quality issues, moreover the authors did not connect MPPT to wind generation system. In Joos, 2008, the authors propose renewable sources based hybrid system for a greenhouse, however, the 
proposed system is only for a single phase. Moreover, in references, designed controllers are based on measurement of various powers (i.e., sources, storage and load), which require more sensors. In Honnery, 2011, the author presented a power generation system for green building; however, the system is valid for only single-phase systems. Authors used FC, but electrolyzer is not incorporated as dump load since, through electrolyzer, hydrogen can be produced which in turn can be used by FC as an input source.

\section{System description}

This system essentially comprised of a self-excited induction generator (SEIG) driven by a wind turbine connected via an uncontrolled rectifier-inverter (AC-DC-AC) system to a synchronous generator (SG) driven by a diesel engine. The synchronous generator is equipped with a voltage regulator and a static exciter. The wind generator and the diesel generator together supply the isolated load power requirement.

\section{System dynamic model}

The dynamic models of the different parts of the system can be described as follows: Diesel side dynamic model. Diesel generation side system consists of diesel engine, synchronous generator and the load which can be modelled as follows: Synchronous generator dynamic modelling. The dynamic mathematical model of the synchronous generator in the $\mathrm{dr}-\mathrm{qr}$ axis synchronously rotating reference frame fixed in the rotor (i.e., $\mathrm{dr}$-qr reference frame rotating at the rotor speed xsg) is given by:

$p i_{q}^{r}=\frac{L_{k q}^{\prime}}{L_{k q}^{\prime}-L_{m q}^{2}}-R_{s i_{q}^{r}}-\frac{L_{k q}^{\prime} L_{m q}^{\prime}}{L_{k q}^{\prime}} i_{k q}^{r}-\omega_{s g i_{d}^{r}}+\omega_{s g L_{m d}} i_{f}^{r}-V_{q}^{r}$

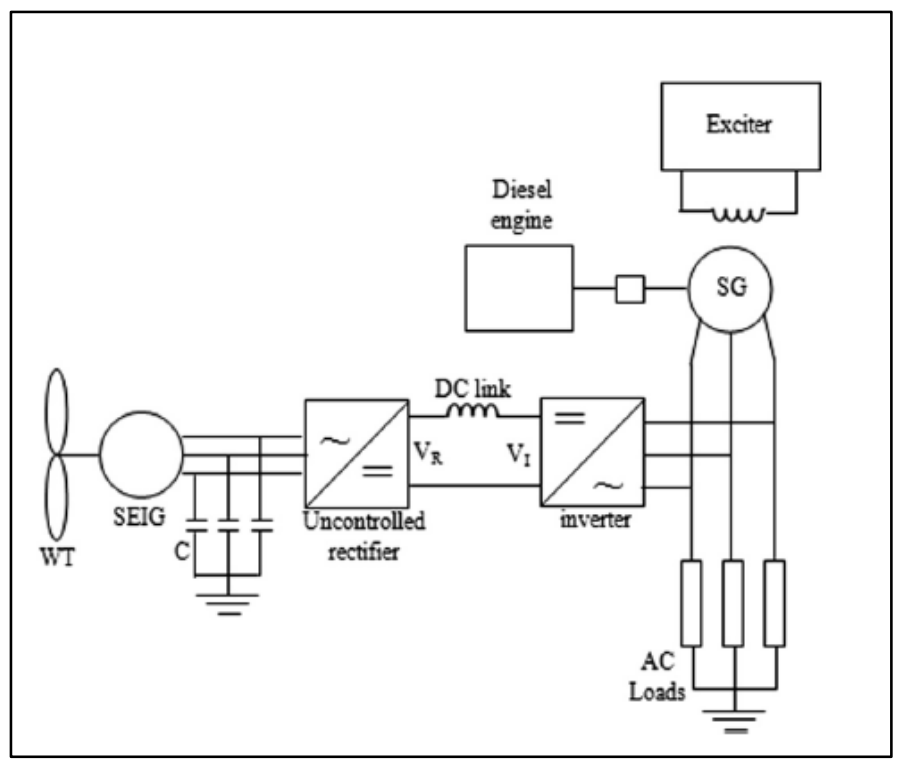

Figure 4: Block Schematic diagram of the proposed hybrid wind-diesel-generation system. 


$$
\begin{aligned}
& p i_{d}^{r}=\frac{1}{K_{11}} \quad\left[\omega_{s g} L_{q} i_{q}^{r}-R_{S} i_{q}^{r}-\omega_{s g} L_{m q} i_{k q}^{r \prime}+\left(K_{22} R_{k d}^{r} L_{f}^{r}+K_{33} R_{k d}^{r} L_{m d}\right) i_{k q}^{r \prime}-\right. \\
& \left(K_{22} L_{m d}+K_{33} L_{k d}^{r}\right) R_{f}^{\prime} i_{f}^{r \prime}+\left(\left(K_{22} L_{m d}+K_{33} L_{k d}^{r}\right) v_{f}^{r^{\prime}}-v_{d}^{r}\right] \\
& p i_{k g}^{r \prime}=\frac{R_{k g}^{\prime}}{L_{k q}^{\prime}} i_{k q}^{r \prime}+K_{44} \quad\left[-R_{s} i_{q}^{r}-\frac{R_{k g}^{\prime} L_{m q}}{L_{k q}^{\prime}} i_{k g}^{r^{\prime}}-\omega_{s g} L_{d} i_{q}^{r}+\omega_{s g} L_{m d} i_{k d}^{r \prime}+\right. \\
& \left.\omega_{s g} L_{m d} i_{f}^{r \prime}-v_{q}^{r}\right] \\
& p i_{k g}^{r \prime}=K_{22} \quad v_{q}^{r}+\frac{\left(L_{m d}-L_{f}^{\prime}\right.}{K_{11}} \quad \omega_{s g} L_{q} i_{q}^{r}-R_{s} i_{d}^{r}-\omega_{s g} L_{m q} i_{k q}^{r \prime}+ \\
& \left(K_{22} L_{f}^{\prime} R_{k d}^{\prime}+K_{33} L_{m d} R_{k d}^{\prime}\right) i_{k d}^{r^{\prime}}-\left(K_{22} L_{m d} R_{k d}^{\prime}+K_{33} L_{k d}^{\prime}\right) R_{f}^{\prime} i_{f}^{r^{\prime}}+\left(K_{22} L_{m d} R_{k d}^{\prime}+\right. \\
& \left.K_{33} L_{k d}^{\prime}\right) v_{f}^{r^{\prime}}-v_{d}^{r}+\frac{\left(R_{k d}^{\prime} L_{f}^{\prime}\right.}{L_{m d}} i_{k d}^{r^{\prime}}-R_{f}^{\prime} i_{f}^{r^{\prime}} \\
& K_{11}=L_{d-} \frac{L_{m d}\left(L_{m d}-L_{f}^{\prime}\right)}{\left(L_{m d}^{2}-L_{f}^{\prime} L_{k d}^{\prime}\right)}-\frac{L_{m d}\left(L_{m d} L_{k d}^{\prime}-L_{m d}^{2}\right)}{\left(L_{f}^{\prime} L_{k d}^{\prime}-L_{m d}^{2}\right)} \\
& K_{22}=\frac{L_{m d}}{\left(L_{m d}^{2}-L_{f}^{\prime} L_{k d}^{\prime}\right)}-K_{33} \frac{L_{m d}}{\left(L_{f}^{\prime} L_{k d}^{\prime}-L_{m d}^{2}\right)}, K_{44}=\frac{L_{m q}}{\left(L_{q} L_{k q}^{\prime}-L_{m q}^{2}\right)} \\
& K_{22}=\frac{L_{k d}^{\prime}}{\left(L_{m d} L_{k d-}^{\prime} L_{m d}^{2}\right)}
\end{aligned}
$$

The qr and dr stator voltages in the reference frame fixed in the rotor are given by:

$$
\begin{aligned}
& v_{q}^{r}=-i_{q}^{r} R_{s}-\omega_{s g} L_{d} i_{d}^{r}+\omega_{s g} L_{m d} i_{k d}^{r}+\omega_{s g} L_{m d} i_{f}^{r \prime} \\
& v_{q}^{r}=-i_{q}^{r} R_{s}+\omega_{s g} L_{q} i_{q}^{r}-\omega_{s g} L_{m q} i_{k q}^{r}
\end{aligned}
$$

The rotor speed wsg is governed by the following differential equation:

$$
\frac{2}{P_{O}}\left(J P \omega_{s g}+f \omega_{s g}=T_{m d}-T_{e}\right.
$$

where Po is the number of poles of the synchronous machine, Tmd is the diesel engine output torque (input torque of the synchronous generator) and Te is the electromagnetic torque, which can be written as: 
$T_{e}=\left(\frac{3}{2}\right)\left(\frac{P_{o}}{2}\right)\left[L_{m d}\left(-i_{d}^{r}+i_{f}^{r^{\prime}}+i_{k d}^{r^{\prime}}\right) i_{q}^{r}-L_{m q}\left(-i_{q}^{r}+i_{d}^{r}\right)\right]$

The torque angle representing the electrical load on the SG is written as follows:

$p \delta=-\frac{2}{P_{O}}\left(\omega_{s g}-\omega_{e}\right)+\delta_{o}$

where wsg and we are the rotor speed and electrical frequency of the synchronous generator respectively and do is the nominal value of the torque angle. It is known that wsg and we are the same in steady-state, but during transient wsg varies and ultimately settles down to the value we. The stator voltages in the reference frame ve $\mathrm{q}$ and ve $\mathrm{d}$ are fixed with the synchronously rotating frame MMF vector and rotating at with angular speed xe which can be written as follows:

$v_{q}^{e}=v_{q}^{z} \cos (\delta)+v_{d}^{z} \sin \sin (\delta)$
$v_{d}^{e}=v_{d}^{r} \sin (\delta)+v_{d}^{z} \cos \cos (\delta)=0$

(12)

$v_{l}=\sqrt{\left({ }_{-} \wedge\right.}-\left(v_{d}^{e}\right)^{2}=v_{q}^{e}$

The initial orientation of $\mathrm{q}$ and $\mathrm{d}$ reference frame is chosen such that ve $\mathrm{d}$ is initially zero and the load voltage:

$V_{L}=v_{d}^{e}$

\section{Voltage regulator and static exciter model}

The load bus voltage is regulated by controlling the synchronous generator excitation voltage using automatic voltage regulator (AVR). The differential equations expressing the excitation system for the synchronous generator can be written as following:

$$
\begin{aligned}
& p v_{c}=\left(V_{\text {Lref- }} V_{L}\right. \\
& p v_{f}^{\prime}=\frac{K_{e} V_{c-} v_{f}^{\prime}}{T_{e}}
\end{aligned}
$$

where Ke and se are the gain and the time constant of the exciter respectively. 


\section{Diesel engine model and speed regulator}

The SG is driven by a diesel engine which regulates the mechanical power input to the generator to balance the electrical load on the machine. If the electrical load on the generator varies due to a change in power drawn by the local load, the rotor speed and hence the electrical frequency tend to change. In such a situation, the torque input to the SG is controlled to regulate the system electrical frequency. The speed error is the input signal and is used to determine the applied fuel flow rate ur depending on the position of the fuel rack which is regulated by the fuel actuator, characterized by a gain $\mathrm{k} 2$ and a time constant $\mathrm{s} 2$. The torque output Tmd of the diesel engine is proportional to the actual fuel flow rate uf but is delayed by the fuel combustion process time delay s1. The torque output of the diesel engine is written as follows:

$T_{m d}=K_{1 \emptyset f} e-T_{1}^{S}$

where $\mathrm{K} 1$ is constant regarding the output torque to the fuel flow rate. The combustion process delay can be approximated using first-order Pad's approximation as follows:

$e^{-T_{1}^{S}}=\frac{\left(\frac{2}{T_{1}}-S\right)}{\left(\frac{2}{T_{1}}-S\right)}$

The actual fuel flow rate uf can be written as following :

$\emptyset_{f}=\frac{K_{2}}{1+T_{2}^{s}} \emptyset_{r}$

where s2 and $\mathrm{K} 2$ and are time constant and gain of the fuel actuator.

The differential equations describing the diesel engine and its speed governor can be written as following:

$$
\begin{aligned}
& P \emptyset_{r}=\omega_{\text {sgref }}-\omega_{s g} \\
& P \emptyset_{f}=\frac{K_{2} \emptyset_{r-\emptyset_{f}}}{T_{2}} \\
& P x_{1}=\frac{4 \emptyset_{f-2 x_{1-}}}{T_{1}} \\
& T_{m d}=K_{1}\left(x_{1}-\emptyset_{f}\right)
\end{aligned}
$$




\section{Wind Side Dynamic Model}

The wind side system is consists of a wind turbine, induction generator and DC-link which can model as follows: Wind turbine dynamic model. The wind turbine is characterized by no dimensional curves of the power coefficient $\mathrm{Cp}$ as a function of both the tip speed ratio, $\mathrm{k}$ and the blade pitch angle, b: In order to fully utilize the available wind energy, the value of k should be maintained at its optimum value. Hence, the power coefficient corresponding to that value will become maximum also. The tip speed ratio $\mathrm{k}$ can be defined as the ratio of the angular rotor speed of the wind turbine to the linear wind speed at the tip of the blades. It can be expressed as follows:

$\lambda=\omega_{t} R / V_{w}$

where $\mathrm{R}$ is the wind turbine rotor radius, $\mathrm{Vw}$ is the wind speed and $\mathrm{xt}$ is the mechanical angular rotor speed of the wind turbine.

The output torque from the wind turbine can be expressed as follows:

$T_{m}=0.5_{P} A R \quad\left[(0.44-0.0167) \beta \sin \sin \left(\frac{\frac{\omega_{t} R}{V_{w}}-3}{15-0.3 \beta}\right)-0.00184\left(\frac{\omega_{t} R}{15-0.3 \beta}\right) \beta\right] V_{w}^{3} / \omega_{t}$

where $\mathrm{q}$ is the air density, and $\mathrm{A}$ is the swept area by the blades.

\section{Induction Generator Dynamic Model}

The dynamic behaviour of the induction generator in the $\mathrm{d}-\mathrm{q}$ axis synchronously rotating reference frame is given by :

$$
\begin{aligned}
p i_{q s}= & A_{s} A_{1} i_{q s}-\left(\omega_{s}+A_{2} \omega_{m} L_{m}\right) i_{d s}+R_{r} A_{2} i_{q r-} R_{1} \omega_{m} L_{r} i_{d r} \\
p i_{d s}= & \left(\omega_{s}+A_{2} \omega_{m} L_{m}\right) i_{q s}-R_{s} A_{1}+R_{1} A_{2} i_{d r}+A_{1} \omega_{m} L_{m} i_{q r-} A_{1} v_{d s} \\
p i_{q r}= & R_{S} A_{2} i_{q s}+A_{2} \omega_{m} L_{s} i_{q s}-A_{3} i_{q r}+\left(-\omega_{s}+A_{1} \omega_{m} L_{S}\right) i_{d r} \\
p i_{q r}= & A_{2} \omega_{m} l_{s} i_{q s}+R_{S} A_{2} i_{q s}+\left(\omega_{s}-A_{1} \omega_{m} L_{S}\right) i_{q r}-A_{3} i_{d r} \\
& +A_{2} v_{d s}
\end{aligned}
$$

where $v_{q s}=0$, due to the choice of axis alignment, and

$$
\begin{aligned}
& A_{1}=L_{r} /\left(L_{s} L_{r}-L_{m}^{2}\right), A_{2}=L_{m} /\left(L_{s} L_{r}-L_{m}^{2}\right) \\
& \text { and } A_{3}=R_{r}\left(1+A_{2} L_{m}^{2}\right) / L_{r}
\end{aligned}
$$

The rotor speed on $\quad \omega_{m}$ is governed by the following differential equation

$T_{m}+T_{e}=(J P+f) \omega_{m} / P$

where $\mathrm{P}$ is the number of poles of the induction generator, Tm is the input torque from the prim-mover, and Te is the electromagnetic torque representing the load on the induction generator (Te is negative for generator action) which is given by: 
$T_{e}=1.5 P L_{m}\left(i_{q s} i_{d r}-i_{d s} i_{d r}\right)$

Eqs. (30) and (31) are combined as

$p \omega_{m}=\left(-f \omega_{m}+P T_{m}+1.5 P^{2} L_{m}\left(i_{q s} i_{d r}-i_{d s} i_{q s}\right)\right) / J$

In this case, the approximation time window is variable. The algorithm, given by the figure below, carries out the approximation with each data collection to generate the most suitable reading between any collected value and that approximated does not exceed the predefined range).

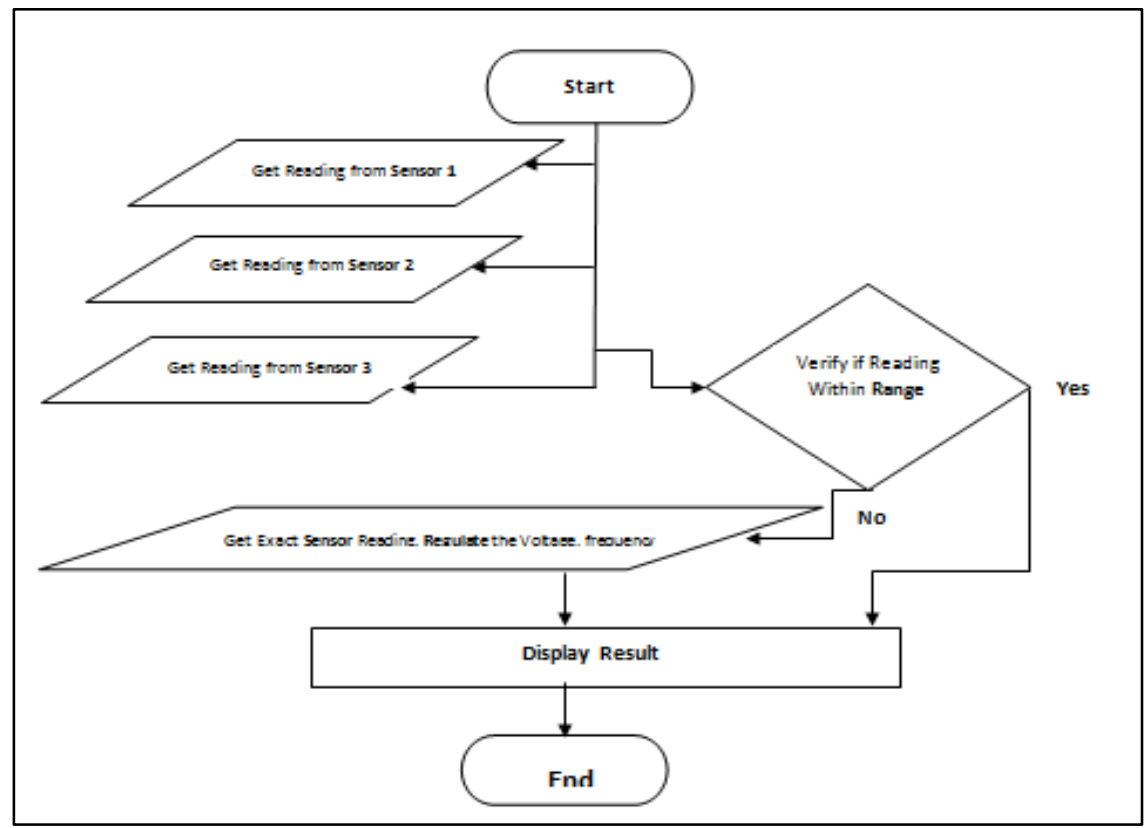

Figure 5: Flowchart for Regulating Algorithm

\section{PERFORMANCE EVALUATION}

This section outlines the overall control strategy of the proposed renewable energy-based hybrid power system. This system consists of a wind turbine, fuel cell, electrolyzer, battery storage unit, diesel generator and a set of loads. The system's overall control strategy is based on a two-level structure. The top-level is the energy management and power regulation (EMPRS) system. Depending on wind and load conditions, this system generates reference operating points to low-level individual subsystems. It also controls the load scheduling operation during unfavourable wind conditions with inadequate energy storage in order to avoid system black-out. Based on the reference operating points of the individual sub-systems, the local controllers control the wind turbine, fuel cell, electrolyzer, battery storage and diesel generator units. The proposed control system is implemented with MATLAB/Simpower software and tested for various wind and load conditions. Results are presented and discussed. 
Table 1: System Parameters

Permanent Magnet Synchronous Generator

$\begin{array}{lr}\text { Number of pole pairs } & 4 \\ \text { Rated speed (rpm) } & 1260 \\ \text { Rated power (kW) } & 1 \\ \text { Stator resistance (ohm) } & 5.8 \\ \text { Direct inductance (mh) } & 0.0448 \\ \text { Quadrature inductance (mh) } & 0.1024 \\ \text { Inertia } & 0.011\end{array}$

\section{Wind Turbine}

Rated power $(\mathrm{kW})$

Base wind speed $(\mathrm{m} / \mathrm{s})$

Series inductance (mh)

\section{RC Filter}

Shunt capacitance (micro F)

\section{Emergency Storage System} ( Section A)

Number of battery in series

Number of battery in parallel

Rated voltage (volt)

Rated current (amp)

Rated capacity (amp-hour)

Emergency Storage System ( Section B)

Number of battery in series

Number of battery in parallel

Rated voltage (volt)

Rated current (amp)

Rated capacity (amp-hour)

Type of fuel cell

\section{Fuel Cell}

Nominal voltage (volt)

Nominal current (amp)

Number of cell

Operating temperature $\left({ }^{\mathrm{O}} \mathrm{c}\right)$

Rated power (kW)

\section{Electrolyzer}

Type of electrolyzer

Alkaline

Number of cell

type

Nominal voltage (volt)

Nominal current (Amp)

Operating temperature $\left({ }^{\mathrm{O}} \mathrm{c}\right)$

80

Rated power $(\mathrm{kW})$

3.6 


\section{Description of the operating points}

Mode 1: High wind conditions $\left(\mathrm{P}_{\text {out }}>\mathrm{P}_{\mathrm{L}}\right),\left(\mathrm{p}_{2} \approx \mathrm{p}_{2} \_\max \right)$ and $\left(\mathrm{SOC} \approx \mathrm{SOC}_{\max }\right)$.

In this mode, the wind turbine extracts optimum power equal to the load demand. The electrolyzer and battery cannot consume any power because the hydrogen tank pressure and the SOC of the battery have reached their maximum limits.

Mode 2: High wind conditions $\left(\mathrm{P}_{\text {out }}>\mathrm{P}_{\mathrm{L}}\right)$ and $\left(\mathrm{P}_{\mathrm{Ex}}>\mathrm{P}_{\mathrm{ELZ}} \mathrm{max}_{\mathrm{max}}+\mathrm{P}_{\mathrm{B}_{-} \max }\right)$.

In this mode, the wind turbine extracts optimum power equal to the load demand plus battery and electrolyzer capacities.

Mode 3: High wind conditions $\left(\mathrm{P}_{\text {out }}>\mathrm{P}_{\mathrm{L}}\right)$ and $\left(\mathrm{P}_{\mathrm{Ex}}<\mathrm{P}_{\mathrm{ELZ}} \mathrm{max}_{\mathrm{max}}+\mathrm{P}_{\mathrm{B}_{-} \max }\right)$.

In this condition, the wind turbine extracts maximum power. Excessive wind power is consumed by the electrolyzer and battery.

Mode 4: Low wind condition $\left(\mathrm{P}_{\text {out }}<\mathrm{P}_{\mathrm{L}}\right),\left(75 \% \leq \mathrm{SOC}<\mathrm{SOC}_{\max }\right)$, and $\left(\mathrm{P}_{\mathrm{FCmin}}<\mathrm{P}_{\mathrm{def}}\right.$ $<$ PFC_max).

In this condition, the wind turbine extracts the maximum available power. The deficit power is provided by the battery and fuel cell during transient conditions. Once the system reaches a steady-state condition, the deficit power is supplied by the fuel cell alone.

Mode 5: Low wind conditions $\left(\mathrm{P}_{\mathrm{out}}<\mathrm{P}_{\mathrm{L}}\right),\left(\mathrm{P}_{\mathrm{FC} \_ \text {max }}<\mathrm{P}_{\mathrm{def}}<\mathrm{P}_{\mathrm{FC} \_\max }+\mathrm{P}_{\mathrm{Bmax}}\right)$, and $(75 \% \leq \mathrm{SOC}$ $\left.<\mathrm{SOC}_{\max }\right)$.

In this condition, the wind turbine extracts the maximum power. The fuel cell provides its maximum power with the battery storage providing the remainder.

Mode 6: Low wind conditions ( $\left.\mathrm{P}_{\text {out }}<\mathrm{P}_{\mathrm{L}}\right),\left(\mathrm{P}_{\mathrm{def}}<\mathrm{P}_{\mathrm{FC} \_ \text {min }}\right)$, and $\left(75 \% \leq \mathrm{SOC}<\mathrm{SOC}_{\max }\right)$.

In this condition, the wind turbine extracts the maximum power while the battery storage provides the necessary power as the power deficit is lower than the minimum power limit of the fuel cell.

Mode 7: Low wind conditions $\left(\mathrm{P}_{\text {out }}<\mathrm{P}_{\mathrm{L}}\right)$, low $\mathrm{SOC}(\mathrm{SOC} \approx 75 \%)$ and (Pdef $<\mathrm{PFC}_{\mathrm{F}}$ min $)$.

In this condition, the wind turbine extracts the maximum power. The battery cannot provide power as the SOC is close to $75 \%$, which is the minimum limit for normal operating conditions. The fuel cell operates in its ohmic zone. Because the power produced by the fuel cell is higher than Pdef, the extra power is used to charge the battery. When the SOC of the battery storage system reaches about $S C_{\max }$, the system operation reverts to Mode 6.

Mode 8: Low wind conditions $\left(\mathrm{P}_{\text {out }}<\mathrm{P}_{\mathrm{L}}\right),\left(\mathrm{P}_{\mathrm{DF}}(30 \%\right.$ of rated load $)+\mathrm{P}_{\mathrm{FC} \_\max }+\mathrm{P}_{\mathrm{Bmax}}>\mathrm{P}_{\text {def }}>$ PFC_max+ PBmax ).

In this condition, the wind turbine cannot meet the load demand. The deficit power is higher than the maximum capacity of the fuel cell and battery storage systems. As a result, the diesel generator must provide power, running on at least $30 \%$ of the rated load. This deficit power 
will primarily be provided by the diesel generator (30\% of rated power), and the remainder by the fuel cell and battery storage system

Mode 9: Emergency conditions - no wind power.

In this condition, the system needs to rely on the diesel generator and battery storage system. If deficit power exceeds the maximum limit of the battery storage and fuel cell, the diesel generator activates. Here, the diesel generator provides at least $30 \%$ of its rated load, with the remainder derived from the fuel cell and battery. In this condition, if the system runs out of hydrogen storage, the EMPRS allows the battery storage to drop as low as $40 \%$.

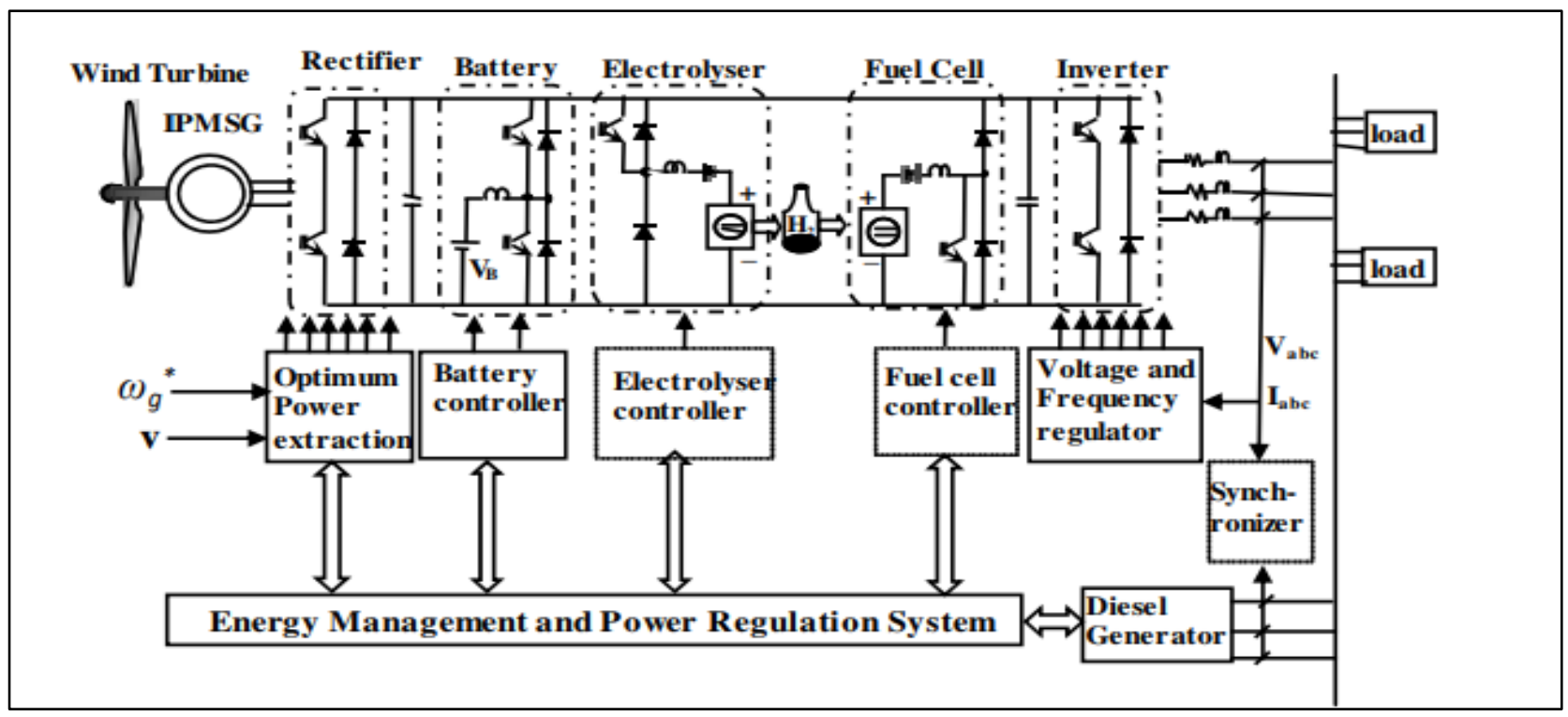

Figure 6: The proposed Hybrid power system.

\section{Wind Profile}

Fig. 7 shows the week-long wind speed from 1-7 January 2017. Fig. 7 indicates that the wind does not follow any trend. From one-year data documents, the average wind speed in 2011 in the area is $7.87 \mathrm{~m} / \mathrm{sec}$ with a standard deviation is 3.44 . The area's maximum wind speed was $22.83 \mathrm{~m} / \mathrm{sec}$.From the data, it is observed that low or no wind conditions can occur for a relatively long period several times annually. Figs 7 and 8 show two cases where low wind conditions occurred for a longer period during the day. It is noted that low or no wind conditions can occur during the peak demand period. 


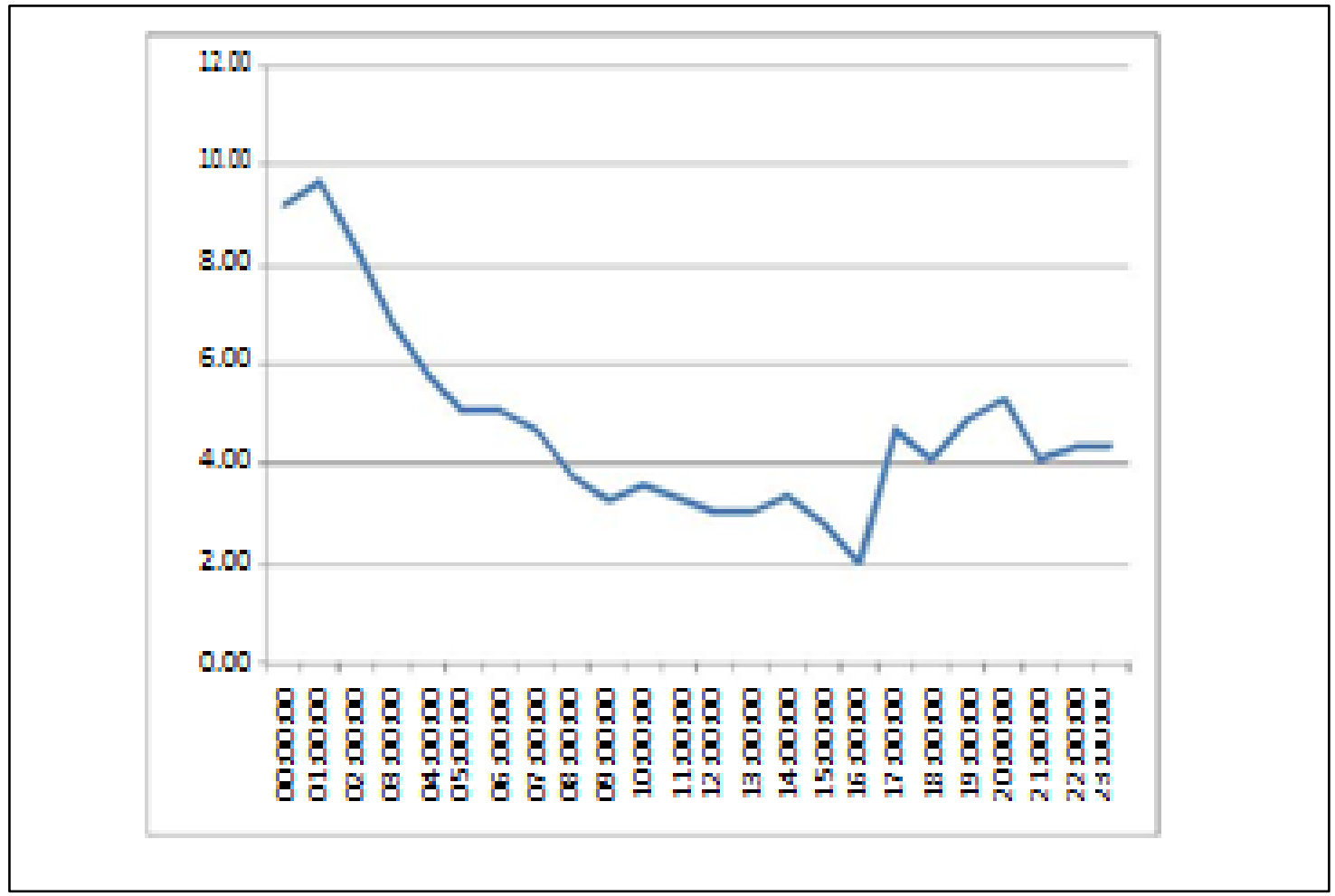

Figure 7: Wind profile from 00:00 hour to 24:00 hour on April 14, 2017.

From Fig. 7, it is seen that from 02:00 hours, wind speed declines. At 7:00 hours, a low wind condition occurs when the wind turbine cannot extract any power. However, at 17:00 hours the wind returns, enabling the turbine to extract power.

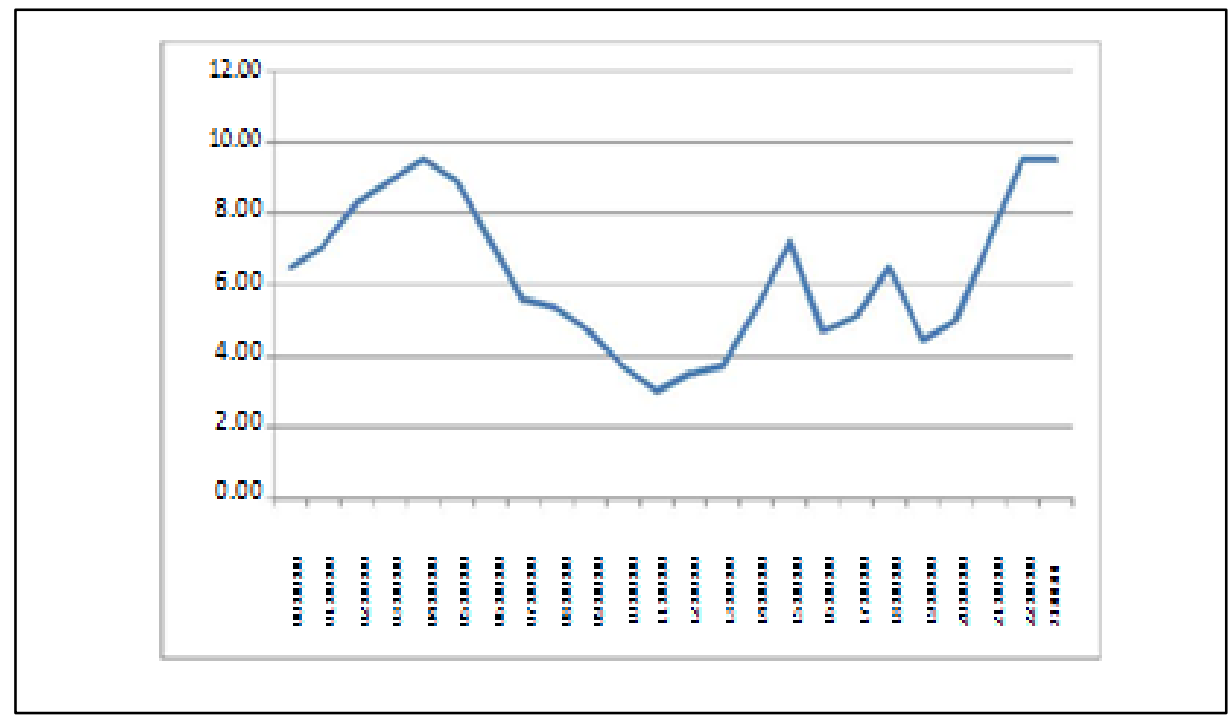

Figure 8: Wind profile from 00:00 hour to 24:00 hour on June 23, 2017. 
From Fig. 8, it is evident that the wind turbine can extract power from 00:00 hours to 9:00 hours. From 09:00 hours to 13:00 hours, a low wind condition prevents the wind turbine from extracting any power. Finally, at approximately 17:00 hours the wind returns.

\section{Load Profile}

The load has a unique characteristic, with a peak generally occurring during mornings and evenings. However, the load demand varies on a seasonal basis. The average load demand in the dry season (December to February) is lower than during the wet season (June to August). Being an attractive tourist destination, the area experiences a higher load demand during the Easter period. The average hourly load demand in the various season are shown in Figs 7-9.

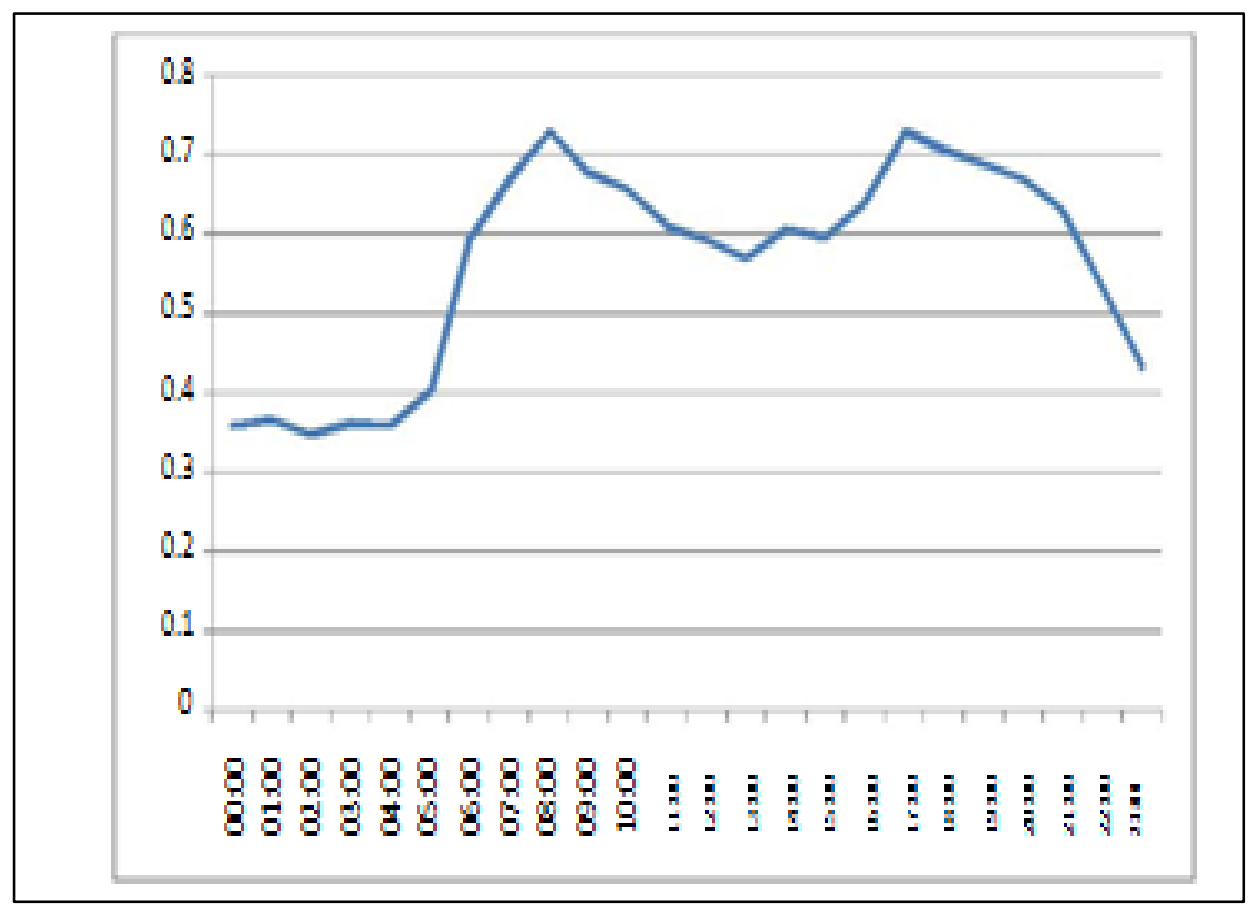

Figure 9: Average hourly load demand during the dry season.

Fig. 9 shows that peak demand in summer occurs between 7:00 am and 9:00 am and between 16:00 pm and 21:00 pm. The morning and evening average peak is about $0.8 \mathrm{MW}$.

\section{Battery management}

The SOC of the battery has to be monitored and maintained within a specific range to ensure a long life operation. The proposed SOC management of the battery under normal conditions is between $75 \%$ - $95 \%$ and between $40 \%$ - $75 \%$ under emergency conditions. 


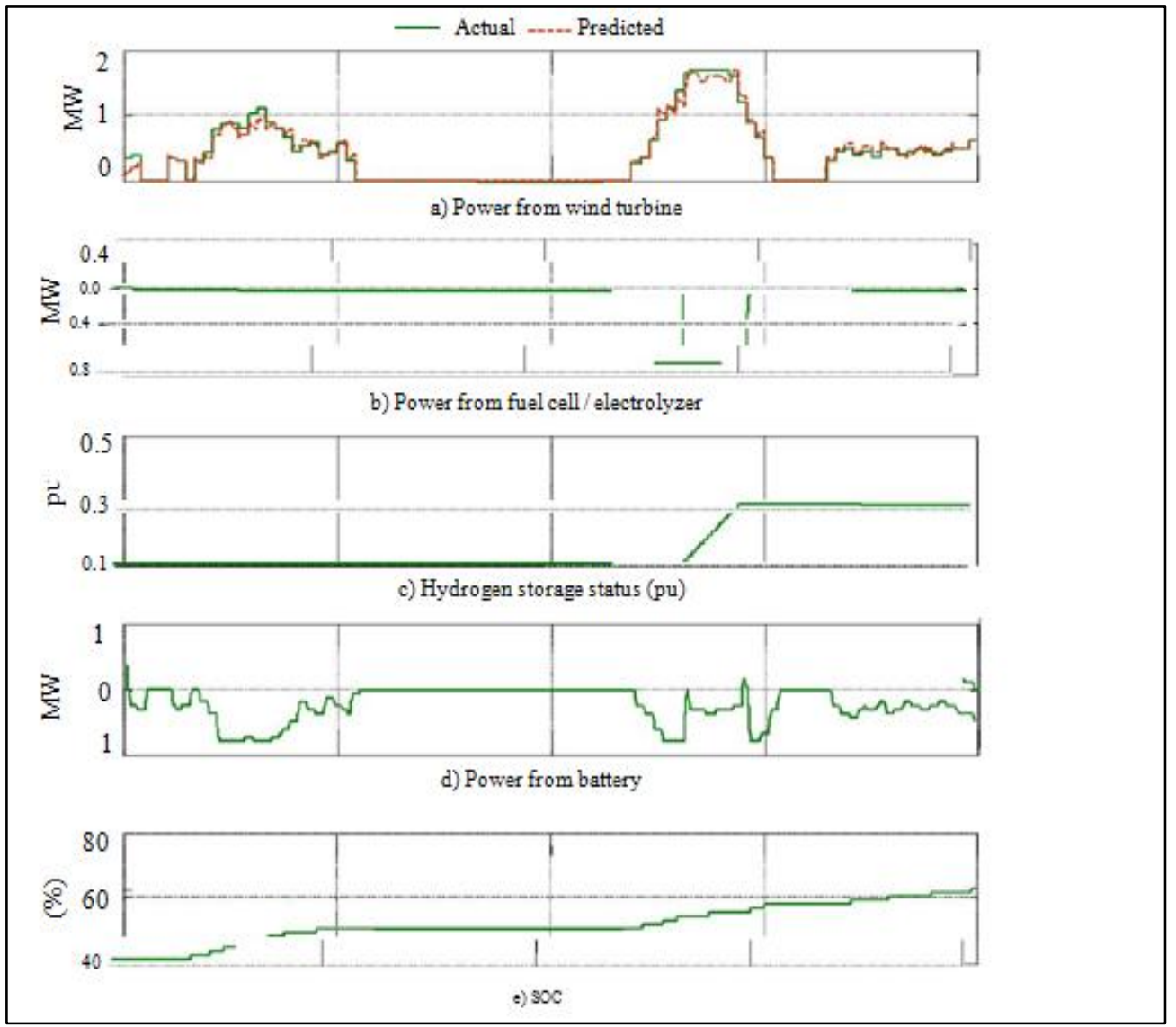

Figure 10 Hybrid system operation under low hydrogen and very low battery storage (emergency operation condition).

\section{DISCUSSION OF FINDINGS}

In this section, several case studies are presented to evaluate the performance of the proposed system during the busy Easter period for different conditions of the battery and hydrogen storage under varying wind and load conditions. In these case studies, the wind profile is chosen such that no wind condition occurs during the peak load. Several different cases of SOC of battery storage and hydrogen storage are considered. From these case studies, it is found that the proposed system can meet the load demand if the status of the SOC of battery storage and the hydrogen storage is high. However, for other conditions, the hybrid system has to curtail loads in order to avoid system black-out. An emergency operation condition is also shown in the case study when the SOC of the battery storage is very low (below 75\%) and hydrogen storage is low. From Fig. 10, the proposed system is able to support only emergency loads for 24 hours. From the case studies, it is also revealed that the hybrid system can avoid system blackouts and is able to supply the emergency loads. The proposed system is designed to operate even in the worst-case scenario. Of course, the power supply cannot be maintained for all the customers all the time, but all essential customers will receive the required power under any worst-case scenario. This is the main advantage of the proposed system. 


\section{CONCLUSION}

This article proposes a control and overall coordination of a hybrid stand-alone power system. The system comprises a wind turbine, fuel cell, electrolyzer, battery storage, diesel generator as well as a set of loads. The overall control strategy of the hybrid system is based on a twolevel structure. The top-level is the energy management and power regulation system. Depending on wind and load conditions, this system generates reference dynamic operating points to low-level individual sub-systems. The energy management and power regulation system also controls the load scheduling operation during unfavourable wind conditions with inadequate energy storage in order to avoid a system black-out. Sequel to dynamic operating points of the individual sub-systems, the local controllers control the wind turbine, fuel cell, electrolyzer and battery storage units. The proposed control system is implemented in MATLAB Simpower software and tested for various wind and load conditions.

\section{REFERENCES}

Ahmed MM, Sulaiman M (2003) Design and proper sizing of solar energy schemes for electricity production in Malaysia. National Power and Energy Conference 2003, pp 268-271

Akhter R, Hoque A (2008) Analysis of a PWM boost inverter for solar home application. World Acad Sci Eng Technol 23

Anegawa T (2010) Characteristics of CHAdeMO quick charging system. In: Proceedings of the EVS-25 Shenzhen, 5-9 Nov 2010

Ardente F, Beccali G, CelluraM(2004) Life cycle assessment of a solar thermal collector. Science Direct

Atlas H, Sharaf AM (2007) A photovoltaic array simulation model for Matlab-Simulink GUI environment. In: Proceedings of IEEE international conference on clean electrical power, ICCEP 2007, Capri

Ayob SM, Yee CH, Muhamad ND, Jusoh A (2005) A new hybrid multilevel inverter topology with harmonics profile improvement. IEEE Trans Power Electron Drives Syst, ISSN: 0-7803-9296- 5/05, pp 999-1002

Banerjee S, Jeevananathan (2010) Modeling of PV array and performance enhancement by MPPT algorithm. Int J Comput Appl 7:35-39 (0975-8887)

Bechtel National (1980) Handbook for battery energy storage in photovoltaic power systems, Final report, SAND80-7022, Feb 1980

Chowdhury AA, Koval DO (2005) Impact of photovoltaic power sources on a power system's capacity reliability levels. I\&CPS

Chowdhury BH, Rahman S (1988) Is central power station photovoltaic power dispatchable? IEEE Trans Energy Convers 3(42):747-754

Conti S, Raiti S, Tina G, Vagliasindi U (2003) Integration of multiple PV units in urban power distribution systems. Sol Energy 75:87-94

Corzine KA, Wielebski MW, Peng FZ, Wang J (2004) Control of cascaded multilevel inverter. IEEE Trans Power Electron 19(3):732-738

Davidson J, The new solar electric home, 20th printing 2001 Duffie JA, Beckman WA (2006) Solar engineering of thermal processes, 3rd edn. Wiley, New York

Dunlop JP (1997) Batteries and charge control in stand-alone photovoltaic systems, Jan 1997 
Egan MG, O’Sullivan DL, Hayes JG (2007) Power-factor-corrected single-stage inductive charger for electric vehicle batteries. IEEE Trans Ind Electron 54:1217-1226.

Huan-Liang Tsai, Ci-Siang Tu, Yi-Jie Su Member, IAENG (2008) Development of generalized photovoltaic model using MATLAB/SIMULINK. In: Proceedings of the world congress on engineering and computer science 2008 WCECS, 22-24 Oct 2008

Hussein KH, Muta I, Hoshino T, Osakada M (2005) Maximum photovoltaic power tracking: an algorithm for rapidly changing atmospheric conditions. IEE Proc Gener Trans Distrib 142 (1):59 IEEE recommended practice for utility interface of a photovoltaic system, IEEE Std. 929-2000 